\title{
Lessons learned: how can we manage the invasion risk from biofuels?
}

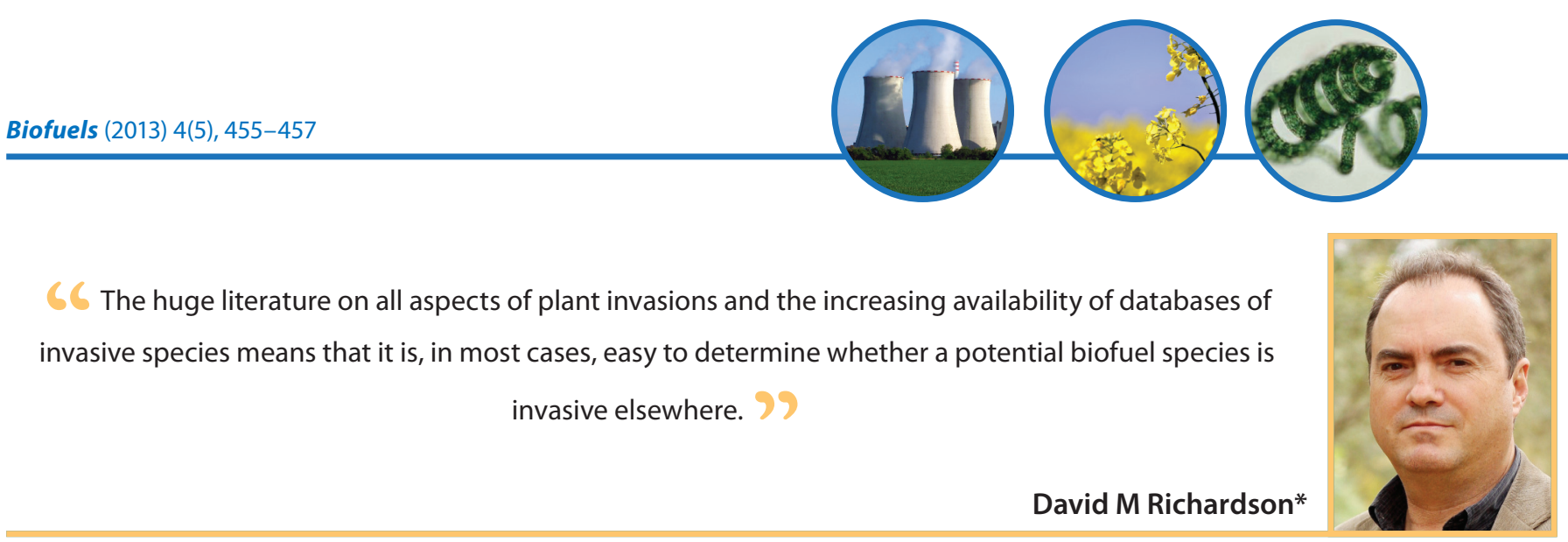

Keywords: biological invasions $\mathbf{m}$ introduction pathways $\mathbf{m}$ invasion science $\mathbf{m}$ mitigation protocols $\mathbf{m}$ risk assessment

Biological invasions are an increasingly important threat to biodiversity and ecosystem functioning worldwide. The numbers of invasive species, the extent of invasions, and the types and overall magnitude of impacts caused by invasive species are increasing rapidly. In many ecosystems invasive species are part of a 'lethal cocktail' of drivers of environmental degradation [1]. Many species that are currently invasive were introduced accidentally, but an increasingly large proportion of invaders, including many of the most damaging species, have been intentionally introduced, and many were used and spread around while providing a variety of benefits to humans. Some of these species are still both useful and harmful in the same region, usually bringing benefits to a (usually small) sector of society but causing harmful (often irreversible) effects, whose costs are generally borne by society at large.

Important advances have been made in understanding the drivers of biological invasions in recent decades we now have a reasonable (but by no means perfect) understanding of the features that make some species successful invaders and some ecosystems particularly susceptible to invasion. We have begun to understand the complex interplay of factors that create and shape pathways along which different species are moved around the world, and how various dimensions of such pathways interact with species traits and many exogenous factors to mediate the outcome of introductions whether introduced species become established, spread and create problems in the ecosystems to which they are introduced [2]. Considerable attention is being given to the human dimension of biological invasions [3]. Much research effort is going into examining the socioeconomic factors that mediate the demand for non-native species to serve diverse needs of human societies and the factors that shape perceptions of these species in different sociopolitical contexts [4]. Since many introduced species are both useful and harmful, strategies for dealing with conflicts of interest that arise are being sought. Research is also seeking insights on the components of risk associated with the importation, propagation and dissemination of non-native species for different human enterprises.

Rapidly growing human populations, changing fashions and fads, and different elements of global change (including climate warming and elevated $\mathrm{CO}_{2}$ levels) are causing unprecedented rapid shifts in introduction pathways on multiple fronts. Aquaculture, 
forestry, horticulture and the pet trade are examples of sectors that have 'sown the seeds' for major invasions in many parts of the world. Research over the past few decades has unraveled many processes associated with selection, introduction, establishment, propagation and dissemination of species associated with these and other sectors; we now know something about how these relate to the propensity for some species to become invasive [5]. The study of biological invasions ('invasion ecology' or 'invasion science') is now one of the most active subfields of ecology; it has thousands of practitioners, dedicated academic centers and its own journals. Invasion science aims to engage with stakeholders to reduce the rate and impacts of biological invasions, while acknowledging that many non-native species have crucial roles in many enterprises [1].

The study of biological invasions ... is now one of the most active subfields of ecology. . 99

Human-mediated climate change and concerns about the sustainability of traditional sources of energy (and links between these drivers) are leading to the formulation of ambitious targets for renewable energy. Many factors will determine how such targets will be achieved in different parts of the world. In many regions a dramatic increase in the use of biofuels is part of the plan; for example, the 2007 Energy Independence and Security Act in the USA. This, along with the predicted rapid displacement of major cultivation zones in some regions, will lead to radical new strategies for prioritizing land use, and a demand for a 'new breed' of plants - adaptable species that can be used for biofuels, as well as for restoration, reforestation and other purposes. Such changes have multiple and hugely profound implications for biodiversity, not least of which is the seemingly inevitable increase in problems of invasiveness of species chosen for cultivation [6]. The case of plants for biofuel production presents a special challenge for environmental management for several reasons.

Most liquid biofuel is currently produced from sugar, grain and vegetable oil, but herbaceous and woody lignocellulosic crops have huge potential for use as feedstocks. Whereas most plants that are used to producing food crops are domesticated (altered at the genetic level through selection to accentuate desirable traits), most plants favored for large-scale biofuel production are wild (non-domesticated) species. Few domesticated crop plants are major weeds (and none are important invaders of natural ecosystems), whereas most good candidates for large-scale biofuel production are inherently weedy and many are already hugely damaging invaders of natural ecosystems. Among the traits shared by many of these species are tolerance of a wide range of environmental conditions (including those that characterize agriculturally marginal sites targeted for biofuel production), physiological adaptations for rapid growth and high fecundity, and general resistance to major pests and diseases [7]. Almost every plant species mentioned in the burgeoning literature on biofuels is either known to be invasive or, in cases where the species has not been widely planted, has the potential to become invasive.

The huge literature on all aspects of plant invasions and the increasing availability of databases of invasive species means that it is, in most cases, easy to determine whether a potential biofuel species is invasive elsewhere. 'Invasive elsewhere?' is a key question in most formal assessments of the risk of a species becoming invasive in a new region [8]. Major advances have also been made in understanding how important particular traits are for conferring invasiveness in particular ecosystems and these insights have been used to apply formal risk-assessment protocols to biofuel plants $[9,10]$.

\footnotetext{
66 If we accept that most biofuel feedstock species pose

high risks of becoming invasive, the challenge then

becomes to modify certain dimensions of the introduction

pathway to minimize the chance of widespread and damaging invasions materializing. 99
}

Special problems arise when applying risk assessments to introduced species when the species in question has a very good chance of becoming invasive and when the primary aim of elucidating risks is to identify potential mitigation options. In many cases, species known to be invasive, or with a very high chance of becoming invasive, will be approved for introduction and planting to produce biofuels, irrespective of the outcome of risk assessments (when sociopolitical considerations override environmental concerns in decision-making). Many publications call for more efforts to identify native biofuel feedstocks or non-weedy alien species [11]. Although such efforts should be encouraged, it seems likely that a suite of inherently weedy non-native species will be widely used in many parts of the world.

If we accept that most biofuel feedstock species pose high risks of becoming invasive, the challenge then becomes to modify certain dimensions of the introduction pathway to minimize the chance of widespread and damaging invasions materializing. Here we need to merge insights from first principles and empirical evidence. Centuries of experience with introducing plants and planting them in different configurations in the landscape for different purposes, be it for agroforestry, commercial forestry, horticulture 
or to stabilize sand dunes, has taught us some lessons that need to be applied when planning biofuel plantings. A few of these that should inform sound biofuels policies are described below [12].

Invasions are triggered and made particularly difficult to manage by the huge numbers of propagules (seeds and other reproductive structures) that are produced when plants are cultivated in large numbers over large areas. Propagules accumulate over time; although invasions may not materialize early in the production cycle of the crop, provision for managing invasions when/if they happen must be built into long-term plans. Biological control to reduce propagule production is feasible in some cases and should be considered at the planning stage. The configuration of plantings and their situation in the landscape defines whether and to what extent conditions are conducive for launching and sustaining invasions. For example, long edges between plantings and adjoining invasible habitats greatly improve the chance of invasions; rows of plants or scattered plants form effective foci for dispersal of certain species. Where plantings adjoin areas of natural or semi-natural vegetation that are managed for other uses, conflicts of interest are assured when invasions eventuate and interventions should be planned. Considerations such as those mentioned above can be used to produce risk maps to prioritize areas for surveillance, monitoring and invention [13]. Risk 'hot spots' can be particular habitats, such as riparian zones, which are known to be highly susceptible to invasion by alien plants, or particular zones within a cultivation unit.

Drivers of biofuel production will be very different in different regions of the world where different factors will be prioritized. Much research is underway to develop protocols and guidelines to ensure that biofuel crops are produced in the most environmentally sustainable manner. Where the issue of invasiveness is mentioned, discussion is usually confined to whether species are invasive or not, and scant attention is paid to the many other dimensions of the pathways created by the introduction and cultivation of biofuel feedstocks for different markets in particular socioeconomic situations. Insights from invasion ecology and landscape ecology are needed to plan for 'designer landscapes for sustainable biofuels' [14] and formulate sound mitigation protocols $[15,16]$.

\section{Financial \& competing interests disclosure}

DM Richardson acknowledges support from the DST-NRF Centre of

Excellence for Invasion Biology and the National Research Foundation (grant no. 85417). The author has no other relevant affiliations or financial involvement with any organization or entity with a financial interest in or financial conflict with the subject matter or materials discussed in the manuscript apart from those disclosed.

No writing assistance was utilized in the production of this manuscript.

\section{References}

1 Pyšek P, Richardson DM. Invasive species, environmental change and management, and ecosystem health. Ann. Rev. Environ. Res. 35 , 25-55 (2010).

2 Wilson JRU, Dormontt EE, Prentis PJ, Lowe AJ, Richardson DM. Something in the way you move: dispersal pathways affect invasion success. Trends Ecol. Evolut. 24, 136-144 (2009).

3 The Great Reshuffling. Human Dimensions of Invasive alien Species. McNeely JA (Ed.). Internation Union for Conservation of Nature - The World Conservation Union, Gland, Switzerland (2001).

4 Kull CA, Shackleton CM, Cunningham PS et al. Adoption, use, and perception of Australian Acacias around the world. Divers. Distrib. 17, 822-836 (2011).

5 Richardson DM. Forestry trees as invasive aliens. Conserv. Biol. 12, 18-26 (1998).

6 Groom MJ, Gray E, Townsend PA. Biofuels and biodiversity: principles for creating better policies for biofuel production. Conserv. Biol. 22, 602-609 (2008).
7 Fargione JE, Plevin RJ, Hill JD. The ecological impact of biofuels. Ann. Rev. Ecol. Evolut. Syst. 41, 351-377 (2010).

8 Kumschick S, Richardson DM. Species-based risk assessments for biological invasions: advances and challenges. Divers. Distribut. doi:10.1111/ddi.12110 (2013) (Epub ahead of print).

9 Davis PB, Menalled FD, Peterson RK, Maxwell BD. Refinement of weed risk assessments for biofuels using Camelina sativa as a model species. J. Appl. Ecol. 48, 989-997 (2011).

10 Gordon DR, Tancig KJ, Onderdonk DA, Gantz CA. Assessing the invasive potential of biofuel species proposed for Florida and the United States using the Australian Weed Risk Assessment. Biomass Bioenerg. 35, 74-79 (2011).

11 Low T, Booth C, Sheppard A. Weedy biofuels: what can be done? Curr. Opin. Environ. Sustain. 3, 55-59 (2011).
12 Richardson DM, Blanchard R. Learning from our mistakes: minimizing problems with invasive biofuel plants. Curr. Opin. Environ. Sustain. 3, 36-42 (2011).

13 Rouget M, Richardson DM, Nel JA, van Wilgen BW. Commerciallyimportant trees as invasive aliens towards spatially explicit risk assessment at a national scale. Biol. Invas. 4, 397-412 (2002).

14 Koh LP, Levang P, Ghazoul J. Designer landscapes for sustainable biofuels. Trends Ecol. Evol. 24, 431-438 (2009).

15 International Union for Conservation of Nature. Guidelines on Biofuels and Invasive Species. International Union for Conservation of Nature, Gland, Switzerland (2009).

16 DiTomaso JM, Reaser JK, Dionigi CP et al. Biofuel vs bioinvasion: seeding policy priorities. Environ. Sci. Technol.44, 6906-6910 (2010). 
